\title{
Zapraksu
}

\section{Kognitivna niša}

\section{Đorđe Petronić, Igor Vujović}

Univerzitet u Istočnom Sarajevu, Filozofski fakultet, Katedra za psihologiju, Pale, Republika Srpska, Bosna i Hercegovina

Primljen - Received: 12/02/2020 Prihvaćen - Accepted: 13/04/2020

\author{
Adresa autora: \\ MsrĐorđe Petronić \\ Vučija Luka 58, 71144 Istočni Stari Grad \\ 065/705-801 \\ djordje.petronic@ffuis.edu.ba
}

Copyright: @2020 Petronić Dj \& Vujović I. This is an Open Access article distributed under the terms of the Creative Commons Attribution 4.0 International (CC BY 4.0) license.

\begin{abstract}
Kratak sadržaj
U zajedničkoj publikaciji sa Alfredom Raselom Volasom, Čarls Darvin je objasnio teoriju po kojoj se svi živi oblici razvijaju putem prirodne selekcije u kojoj je borba za opstanak imala efekat sličan vještačkoj selekciji koja se primjenjuje u selektivnom uzgoju. Pored podudarnosti gledišta o nastanku živog svijeta, ova dva naučnika imala su i neslaganja. Volas je tvrdio da inteligencija nikada nije mogla nastati kroz prirodnu adaptaciju, nego kao posljedica inteligentnog dizajna (intelligent design). Darvin je insistirao na tome da se ljudska inteligencija u potpunosti može objasniti teorijom evolucije. Ova razlika u gledištima ustvari je manifestacija različitosti u nastojanju da se odgovori na pitanje: "Zašto su ljudi tako pametni?"
\end{abstract}

U tom kontekstu, osnovni cilj ovog rada je izvršiti pregled literature iz evolucione psihologije i predstaviti objašnjenje evolucije ljudske inteligencije. Drugim riječima, ovim radom nastoji se objasniti zbog čega su ljudi danas u mogućnosti ostvariti takve intelektualne podvige kao što su matematika, nauka, filozofija, pravo itd, imajući u vidu da se ovakve sposobnosti ili talenti ne mogu naći u staništu iz koga su ljudi evoluirali. Rezultati su pokazali da evolucioni psiholozi smatraju da su ljudi tako inteligentni, jer su evoluirali kako bi popunili "kognitivnu nišu". Kognitivna niša predstavlja način preživaljavanja koji karakteriše upravljanje okruženjem posredstvom kognicije i socijalne saradnje.

Ključne riječi: inteligencija, kognitivna niša, evolucija, adaptacija

\section{Koncept kognitivne niše}

Pojam "kognitivna niša" prvi su predložili Tooby i DeVore [1] kako bi bez oslanjanja na "egzotične" evolucione mehanizme (inteligentni dizajn ${ }^{1}$ i sl.) objasnili konstelaciju zoološki neobičnih osobina modernog čovjeka, Homo sapiensa.

Svoje objašnjenje započinju uobičajenom biološkom postavkom po kojoj organizmi evoluiraju na račun drugih organizama. Tako je praktično svaki izvor hrane, u stvari, dio tijela nekog drugog organizma. Ovaj biološki mehanizam posebno je lako uočiti kod životinja koje su mesojedi i koje

1 Koncept inteligentnog dizajna u suprotnosti je sa konvencionalnim biološkim naukama koje nastoje naučnim metodama objasniti život kroz procese mutacije i prirodne selekcije. Volas nastoji da objasni sljedeći paradoks - pretpostavlja da je mozak praistorijskog (divljeg) čovjeka neznatno inferiorniji po svojoj strukturi i kompleksnosti od mozga današnjeg Evropljanina. Umajući to u vidu, logično je pretpostaviti da bi bio sposoban, pod sličnim uslovima razvoja, ostvariti i slične prosječne rezultate, kao i savremeni čovjek. Ali, mentalni zahtjevi najnižih divljaka su veoma mali, jedva iznad mnogih životinja. Kako je onda taj mozak toliko razvijen, iznad potreba njegovih vlasnika? Prirodna selekcija mogla bi doprinijeti da mozak divljaka bude samo malo bolji od mozga majmuna. Odgovor na ovaj paradoks Volas vidi u intervenciji neke "više inteligencije" koja nas je vještački učinila ljudima [3]. 
preživljavaju konzumacijom tijela drugih organizama. Međutim, ovaj mehanizam ne ograničava se samo na populaciju mesojeda, jer i životinje koje su biljojedi preživljavaju konzumacijom biljaka, koje su takođe organizmi. Čak i biljke apsorbuju elemente koji su bili u sastavu drugih organizama [1]. Pinker [2] dalje objašnjava da svaki organizam nastoji razviti efikasnu strategiju kojom se nastoji zaštititi od toga da bude pojeden. Životinje tako razvijaju brzinu ili snagu kako bi pobjegle ili se borile sa predatorom, oklope ili odbrambene manevre kojim se štite od napada itd. Biljke, takođe, ispoljavaju tendenciju ka odbrambenom "ponašanju", najčešće kroz hemijsku odbranu tako što postaju otrovne ili iritantne pri konzumaciji, ili su jednostavno lošeg ukusa. Sa druge strane, životinje koje se hrane biljkama razvijaju svoje mehanizme kojima nastoje da se probiju kroz ovu odbranu tako što teže biti brže i snažnije od svog plijena, ili tako što će razviti imunost na otrovnost ili iritantnost biljaka koje konzumiraju. Ovaj proces kojim se osnažuju kapaciteti za napad kod predatora, kod plijena pokreće mehanizam za ojačavanjem kapaciteta za odbranu. Ova svojevrsna "biološka trka u naoružanju" između predatora i plijena eskalira procesima prirodne selekcije kroz smjenu više generacija.

Tooby i DeVore [1] sugerišu da ljudi koriste kognitivnu nišu u ekosistemu u kojem žive. U biologiji, niša se može definisati kao oblik preživljavanja organizma ili vrste na posebnom mjestu u opštoj ekonomiji prirode i mrežama ishrane [4]. Pojam kognitivne niše [2] predstavlja daljnje proširenje ovog koncepta, a bazira se na ideji da u svakom ekosistemu postoji vjerovatnoća da se jedan organizam probije kroz mehanizme odbrane drugog organizma korišćenjem kognitivnih mehanizama, kao što su uzročno-posljedično rezonovanje i udruživanje radi kooperativnosti. Drugim riječima, organizam, kako bi se probio kroz odbranu drugih organizma i iskoristio njihove resurse, unapređuje informacije i svoje znanje o svijetu koji ga okružuje. Sa druge strane, udruživanjem sa drugim jedinkama u mogućnosti je da postigne ciljeve koje ga kao samca uveliko prevazilaze. Na taj način organizam se razvija što za posljedicu ima efikasnije prilagođavanje i preživaljavanje. Ovi mehanizmi rezonovanja i udruživanja odvijaju se internalno u mentalnim modelima svijeta, a rukovođeni su intuitionim koncepcijama nauke ${ }^{2}$. Zahvaljujući unapređivanju mentalnih umjesto fizičkih ili hemijskih performansi, ljudi su bili sposobni da izrađuju alate, zamke i oružje, da neutrališu štetne supstance iz otrovnih biljaka, a sintetišu korisne iz ljekovitih ili hranljivih. Udružuju se i sarađuju sa drugim ljudima u različitim aktivnostima, od igre do lova. Ove kognitivne strategije obrazuju se u vrtlogu beskrajnih kombinacija odgovora na podražaje iz lokalne ekologije (sredine). Nastaju mentalnim dizajnom, koriste se, testiraju i koriguju povratnim informacijama za vrijeme životnog vijeka pojedinaca, a ne sporom nasumičnom genetskom mutacijom. Razvoj kognitivnih strategija u odnosu na fizičke ili hemijske je neuporedivo brži, što ljudima daje ogromnu prednost u evolucionoj trci u naoružanju protiv koje se druge životinje ne mogu braniti. Čak i prije aktuelnog antropoidnog masovnog izumiranja, smatra se da su praistorijski ljudi prouzrokovali značajna izumiranja velike faune, jer su se kognitivni mehanizmi ljudi razvili toliko brzo u realnom vremenu da ostali ogranizmi nisu imali šansu da razviju mehanizme kojima bi se od njih branili [2].

Arheološki podaci nam dokazuju da su ljudi praktikovali lov i sakupljanje mnogo prije nego što je ta aktivnost ustupila mjesto gajenju domaćih životinja i kultura (što smatra da se deslio prije samo 10 000-12 000 godina). Ovu tvrdnju potkrepljuju dokazi u vidu kamenih alata i komplementarnih dokaza o rezovima na kostima, za koje se smatra da datiraju od prije 800000 godina. Do direktnih dokaza o aktivnom lovu od prije 400000 godina došlo je i otkrićem artefakata koji su identifikovani kao lovačka koplja zbog svojih izvanrednih svojstava. Na dužini od oko dva metra napravljeni su tako da imaju oblik i raspored težine koplja, što sugeriše da su napravljeni da budu bačeni, za razliku od kopalja za probadanje. Njihova sofisticiranost sugeriše da su oni bili

2 Intuitivne koncepcije nauke (hemije, fizike, psihologije) nastale na temelju svakodnevnog iskustva. Zaključivanje se odvija intuitivnom, umjesto naučnom logikom koju kakarteriše skepticizam. To su specifična znanja koja se prenose $u$ obliku narodnog znanja sa jedne generacije na drugu. 
napravljeni zahvaljujući dugom periodu kumulativnog kognitivnog razvoja. Ovi dokazi o ubijanju velikih sisara, kao što su nosorozi i slonovi, porijeklo je ovih izrazito homininskih oblika lova i predstavlja nešto što je izvan svega što se vidi kod drugih primata [5].

Teorija kognitivne niše pomaže da se objasne mnoge zoološki čudne karakteritike Homo sapiensa, osobine koje su univerzalne za ljudsku kulturu, ali su jednistvene ili hiperrazvijene $u$ odnosu na ostatak životinjskog carstva. Tri elementa preko kojih je moguće operacionalizovati kognitivnu nišu su: tehnološko znanje, kooperacija i gramatički jezik [2].

\section{Tehnološko znanje}

Ljudi, za razliku od drugih vrsta, koriste i zavise od alata koji uključuju više dijelova i zahtijevaju komplikovane metode izrade. Pravljenje ovih alata bilo je moguće zahvaljujući razvoju mehanizama uzročno poljedičnog rezonovanja koji su omogućili anticipaciju efekata manipulacije okolnim svijetom. Alati se koriste u proširenim segmentima ponašanja i stiču se individualnim otkrićem i učenjem od drugih. Služe za hvatanje i ubijanje životinja, prerađivanje hrane (kuvanje, fermentaciju, namakanje, drobljenje kako bi se odstranili otrovi ili povećala dostupnost nutritivnih sastojaka iz hrane), generisanje lijekova iz ljekovitog bilja. Ovo rezonovanje potkrepljeno je intuitivnim teorijama-narodnim razumijevanjem fizike (objekata, supstanci i sila koje djeluju), geometrije (mjesta, puteva i pravaca), biologije (materije koje organizmu daju formu i pokreću ga), psihologije (unutrašnja nematerijalna uvjerenja i želje) [6].

\section{Kooperacija}

Udruživanje radi kooperativnosti omogućilo je postizanje svih ciljeva koji su individualno bili nedostižni. Ljudi su naučili da sarađuju sa drugim ljudima: trguju dobrima, obavljaju usluge, razmjenjuju znanja, zajedno podižu djecu, love, sakupljaju plodove i brane se. Ova kooperativnost proširuje se i na ljude izvan krvnog srodstva kroz partnerstvo, koalicije, trgovinske veze i sl. [7].

Evolucija saradnje kroz recipročni altruizam zahtijeva kognitivne adaptivne mehanizme koji izgleda da su posebno dobro razvijeni kod ljudi. Oni uključuju: kapacitete za raspoznavanje pojedinaca, epizodičku memoriju za njihove akcije, sposobnost klasifikovanja tih akcija u smislu utvrđivanja da li krše reciprocitet osjećanja. Zatim, skup moralnih emocija kao što su empatija, zahvalnost, ljutnja, krivica i povjerenje kojima se podstiče saradnja, nagrađuju reciprocitatori, a kažnjavaju varalice. I na kraju, drajvere kojima se procjenjuje kompetentnost, integritet i velikodušnost drugih ljudi, kao i drajvere kojima se stvara vlastita reputacija za ove osobine [2].

\section{Gramatički jezik}

Iako mnoge životinje komuniciraju, ljudi su, izgleda, jedinstveni u upotrebi otvorenog kombinatornog sistema, gramatičkog jezika. Iako svaki jezik mora biti naučen, ljudi imaju posebnu sposobnost sakupljanja, učenja i tvorenja novih riječi i pravila tako da ne zavise od drugih vrsta kao nastavnika (kakav je slučaj sa majmunima). Gramatički jezik ima jasne prednosti u prenosu informacija, jer poruke ne moraju biti dio konačnog repertoara nego mogu da se sastoje od elemenata, što pruža mogućnot neograničenog izražavanja novih poruka. Tako npr. ukoliko pas ujede čovjeka to nije vijest, međutim, ukoliko čovjek ujede psa, e to je vijest. Iz primjera vidimo da nam moć gramatike dozvoljava da prenosimo informacije organizujući poznate riječi u nove kombinacije. Kao i drugi kombinatorni sistemi u biologiji (DNK, RNK), jezik dozvoljava obrazovanje ogromnog broja strukturalnih kombinacija. Broj mogućih rečenica, od kojih svaka prenosi različitu poru$\mathrm{ku}$, proporcionalan je broju pozicija u kojima se mogu naći riječi u rečenici. Npr. ukoliko riječi u rečenici mogu da se nađu na deset različitih pozicija, tipičan govornik mogao bi da izgovori barem $10^{20}$ različitih rečenica [8].

Korisnici jezika mogu da dijele neograničen broj poruka koje se tiču specifičnih događaja (ko je i šta uradio kome, zašto, kada i gdje), generalizovane ekspertize (da bi to postigli, treba uraditi to i to) i fleksibilni socijalni ugovori (ako to uradi tim, ja ću uraditi to i to). Zahvaljujući gramatičkom jeziku moguće je da jedinka koja je izuzetno nadarena ili srećnim slučajem dođe do 
određenih spoznaja svoja saznanja prenese na druge jedinke, tako da i one dođu do spoznanje iako nisu imale nikakvog direktnog iskustva sa predmetom spoznaje [9].

Ova tri opisana mehanizma koja su se razvila u toku evolucije prouzrokovala su dalji razvoj osobina koje su tipične samo za ljude ili su u tako velikom stepenu razvijene samo kod ljudi. Ljudska vrsta naselila je staništa širom svijeta. Ljudi imaju produženo djetinjstvo u odnosu na ostale životinje. Razvijaju i njeguju kulturu [2].

\section{Još neke osobine karakteristične za ljude}

U određenom stepenu, širok spektar staništa koje naša vrsta iskorištava i raznolikost $u$ načinu ishrane od jednog staništa do drugog mogu biti objašnjeni prirodnom selekcijom gena u lokalnoj populaciji usljed djelovanja ambijentalnih uslova. Međutim, ove adaptacije su slabe u poređenju sa onim što je omogućila ljudska tehnologija. Inuitska kolonizacija visokih geografskih širina olakašana je tjelesnim promjenama i pigmentacijom kože, ali je mnogo više zavisila od kajaka, harpuna, igloa. Ovdje možemo vidjeti koliko se kognitivna niša razlikuje od drugih primjera niša u biologiji [10].

Pored toga, našu vrstu odlikuje produženo djetinjstvo u kojem mlada jedinka uči i sakuplja znanje neophodno za adaptaciju u odraslom dobu. Ljudsko djetinjstvo produžuje se skoro na cijeli život, jer ljudi jedan veliki dio svog života provode kao djeca, a drugi dio provode kao roditelji, podižući svoju djecu. Ljudske mlade jedinke rađaju se nedovoljno opremljene obrascima i mehanizmima ponašanja za samostalno preživljavanje. Zbog toga dolazi do produženja roditeljstva kako bi roditelji svoju djecu, kroz proces učenja, bili u stanju učiniti u potpunosti funkcionalnim ljudskim bićima. Kao rezultat dugog perioda zavisnosti djeteta, muškarci su prinuđeni da se umjesto traženja prilike za parenje posvete osiguranju opstanka svoje djece. Sve ovo rezultiralo je da ljudi imaju kompleksan i karakterističan sklop seksualnosti. O potomcima se brinu oba roditelja, pa muškarci i žene na duži period ostaju zajedno pri čemu je i vrijeme parenja produženo. Toliko izražena potreba za brigom muškaraca o svojim osjetljivim potomci- ma jedinstvena je i neobična za sisare [2].

Na kraju, važno je spomenuti i kulturalnu podijeljenost ljudske vrste prema jeziku, običajima, normama ishrane i tako dalje, koja se javlja kao posljedica zavisnosti od učenja informacija (o tehnikama preživljavanja, izrade alata, dogovora oko saradnje, običaja) i produžene roditeljske brige o djeci. Dijeljenje znanja između članova jedne grupe dovodi do njegove akumulacije i ako s vremenom grupe gube kontakt jedna sa drugom, počinju kulturalno sve više da se razlikuju [10].

\section{Evolucija čovjeka i kognitivna niša}

S obzirom na očigledne prednosti iskorištavanja okoline korištenjem tehnologije i saradnje, možemo postaviti sljedeća pitanja: Zašto smo samo mi ušli u kognitivnu nišu? Šta je to tako posebno za ljudsku vrstu? Zbog čega je naš majmunoliki predak krenuo stazom koja je rezultirala da se mi danas nalazimo na poziciji na kojoj se nalazimo? Pinker [11] ovo pitanje smatra izuzetno teškim, čak i nemogućim za precizan odgovor, ali ipak iznosi nekoliko pretpostavki.

Prije svega, u javnosti je vrlo često pogrešno shvatanje da je inteligencija konačan cilj evolucije. Ideja da evolucija prirodno usmjerava razvoj organizama ka smjeru u kojem se čovjek razvija je pogrešno shvatanje funkcije prirodne selekcije. Mehanizam prirodne selekcije jednostavno ne funkcioniše po intelektualnim ili moralnim načelima. Zbog toga razvoj inteligencije kakav je karakterističan za čovjeka nije svojstven drugim organizmima [2].

Važno je i shvatiti da inteligencija nije resurs koji ništa ne košta organizam. Pored brojnih prednosti ona ima i nedostatke. Prije svega, inteligencija zahtijeva veliki mozak. Tako veliki mozak ima metabiličke zahtjeve jer zauzima oko $2 \%$ mase našeg tijela, a zahtijeva približno $20 \%$ od ukupno utrošene glukoze i kiseonika u našem tijelu. Nadalje, zahtijeva specifičnu anatomiju ženske karlice kako bi bilo moguće poroditi potomstvo sa tako velikom glavom. Takođe, bitno je i napomenuti da ovako kompleksan organ nosi i rizik od povreda pri rođenju, oboljenja mozga, genskim mutacijama, povredama mozga i sl. Sada se može postaviti pitanje koje su to okolnosti učinile da korisnosti inteligencije pre- 
vazilaze sve zahtjeve i nedostatke koje smo pomenuli. Pretpostavlja se da su homoidni preci, više nego bilo koja druga vrsta, imali splet osobina koje su doprinosile da se dalje ulaganje $u$ inteligenciju isplati [2].

Jedan od faktora za koje se može smatrati da je ovo omogućio je uspravan hod i osjetljivost ruke. Uspravnim hodom ruke su slobodne tako da je bilo moguće inteligenciju prevesti $u$ alate i tehnologiju, što znači da nismo imali samo inteligentne misli nego smo uz pomoć ruku imali mogućnost da uradimo nešto sa njima [12].

Drugi faktor koje je moguće doprinosio evoluciji inteligencije možemo tražiti u ishrani, koja je uključivala meso i druge sastojke bogate proteinima. Meso ne predstavlja samo koncentrisan izvor hranljivih sastojaka za gladni mozak, nego je moguće da je konzumiranje mesa indirektno provociralo razvoj inteligencije jer je potrebno mnogo više pameti da se nadmudri životinja, nego voće ili lišće [12].

Sljedeći faktor za koji se vjeruje da je takođe pridonio je život u grupi. Ovaj način života pruža mogućnost pozitivnih povratnih informacija. $\mathrm{Na}$ taj način podstiče se razvoj socijalne inteligencije. Takođe, grupe omogućavaju da se stečene vještine dijele među članovima, dalje usavršavaju i modifikuju. Indirektnu podršku tvrdnji da su faktori koji su obrazloženi doprinijeli evoluciji ljudske inteligencije pružaju komparativne studije koje pokazuju da je veća inteligencija životnjskih vrsta povezana sa veličinom mozga, mesožderstvom, veličinom grupe, produženim djetinjstvom i dužim životnim vijekom [12].

\section{Koevolucija kognicije, jezika i društva}

Očigledna međuzavisnost povezuje jezik i znanje. Krajnji proizvod učenja predstavlja vještina preživljavanja koja je kao informacija pohranjena u mozgu. Jezik je sredstvo kojim se ta informacija prenosi na drugi mozak. To znači da sposobnost razmjene informacija putem jezika povećava vrijednost novih znanja i vještina. Jedinka ne mora sama da iskusi pokušaje i greške, srećne okolnosti, udarce ili da ima genijalnost drugih pojedinaca da bi gradila na njihovim otkrićima [13].

Jezik ne samo da umanjuje troškove sticanja vještina nego i uvećava korist. Znanje ne služi samo za manipulaciju u okruženju, nego može predstavljati resurs za razmjenu sa srodnicima ili saradnicima. Drugim riječima, znanje je "neprikosnoveno dobro" jer se može dijeliti bez gubitaka. Ovo se može objasniti sljedećim primjerom. Ukoliko jedna strana drugoj da ribu, više je neće imati. Međutim, ukoliko jedna strana drugu poduči pecanju, ribu će imati obje strane. Jezik omogućava umnožavanje znanja, jer za nekoliko sekundi daha govornik može slušaocu prenijeti neprocjenjivu korist od novog znanja. Na taj način ljudi mogu trgovati ne samo robom nego znanjem i uslugama [2].

Preko jezika moguće je podstaći saradnju među ljudima, ali jezik se zasniva na saradnji zbog toga što nema koristi u dijeljenju informacija sa protivnicima. Nerazdvojiva usklađenost između jezika, inteligencije, društvenosti, unapređenog roditeljstva, produženog djetinjstva i životnog vijeka, te različitog staništa i izvora hrane sugeriše da su ove karakteristike koherentne kao karakterizacija (operacionalizacija) kognitivne niše. S vremenskog odredišta za pretpostaviti je da su se odgovarajuća prilagođavanja postepeno povećavala, počevši od prve vrste hominida koji su imali minimalnu kombinaciju preduslova (bipedalnost, grupni život, omniorija) koja se usložnjavala kroz vrste koje su pokazivale znakove upotrebljavanja alata, saradnje, govora i ponašanja modernog homosapiensa [13].

Pinker [2] smatra da teorija kognitivne niše ima nekoliko prednosti kao objašnjenje evolucije ljudskog uma. Ona uključuje činjenice o kognitivnim, afektivnim i lingvističkim mehanizmima koji su otkriveni savremenom psihološkom naukom, a ne privlačnim, nejasnim, pseudonaučnim crnim kutijama poput "simboličnog ponašanja" ili "kulture". Konkretnije rečeno, kognitivne adaptacije obuhvataju "intuitivne teorije" fizike, biologije i psihologije, kooperativne adaptacije obuhvataju moralne emocije i mehanizme za pamćenje pojedinaca i njihovih postupaka, dok lingvističke adaptacije obuhvataju kombinatorne alate za manipulaciju gramatičkim, sinaksičkim i fonološkim jedinicama. Teorijom kognitivne niše ne zahtijeva se radikalna revizija teorija evolucije. Iako je upotreba gramatičkog jezika jedinstvena za ljude, a naša inteligencija i društvo izuzetno razvijeni, nije neuobičajeno da prirodna 
selekcija razvija jedinstvene i ekstremne osobine (surla kod slona, armadilov oklop i sl.) ukoliko one imaju praktične koristi. A rezonovanje, kooperativnost i komunikacija definitivno imaju praktične prednosti.

\section{Zaključak}

Evaluacija ljudskog uma zanimljiva je misterija koja je bila, a i danas je, predmet debate između dva naučnika koja su postavila teoriju evolucije, Darvina i Volasa. Teorija kognitivne niše u duhu je Darvinove koncepcije evolucije. Prema teoriji kognitivne niše homidi su evoluirali u pravcu specijalizacije kognitivne niše koja je definisana kao: uzročno-posljedično rezonovanje, saradnja

Izvor finansiranja. Autori nisu dobili sredstva namijenjena ovom istraživanju.

Etičko odobrenje. Članak ne sadrži nijednu studiju sa ljudima koju je izveo bilo koji od autora.

Sukob interesa. Autori izjavljuju da nemaju sukob interesa.

\section{Literatura}

1. Tooby J, DeVore I. The Reconstruction of Hominid Behavioral Evolution Through Strategic Modeling. In: Maynard-Smith J, editor. Evolution of Social Behaviour Patterns in Primates and Man. Proceedings of the British Academy 88. London: The British Academy; 1987. p. 182-237.

2. Pinker S. The cognitive niche: Coevolution of intelligence, sociality, and language. Proc Natl Acad Sci USA 2010;107(Suppl):8993-9.

3. Glickman SE. Charles Darwin, Alfred Russel Wallace, and the Evolution / Creation of the Human Brain And Mind. Gayana, 2009;73:32-41.

4. Pocheville A. The Ecological Niche: History and Recent Controversies. In: Heams T, et al, editors. Handbook of Evolutionary Thinking in the Sciences. Dordrecht: Springer. 2015. p. 547-86.

5. Whiten A, Erdal D. The human socio-cognitive niche and its. Philos Trans R Soc Lond B Biol Sci 2012;367(1599): 2119-29. sa drugim ljudima i dijeljenje znanja i ugovora kroz gramatički jezik. Elementi ove tročlane adaptacije zajedno su evoluirali sa ostalim osobinama karakterističnim za homide (biroditeljsko staranje, duži životni vijek, duže djetinjstvo itd.).

Iako su adaptacije u kognitivnoj niši očigledne prednosti u bilo kojoj životnoj sredini, one su nedovoljne za formiranje modernih institucija kao što su vlada ili nauka. Tokom istorije i vlastitog obrazovanja ljudi su se prilagodili ovim novijim društvenim tvorevinama kroz proces metaforične apstrakcije, u kojoj su kognitivne šeme i društvene emocije evoluirale tako da je jedan domen podređen i stavljen u službu drugog koji predstavlja sve kompleksniju mentalnu strukturu.

Funding source. The authors received no specific funding for this work.

Ethical approval. This article does not contain any studies with human participants performed by any of the authors.

Conflicts of interest. The authors declare no conflict of interest.

6. Kingdon J. Self-Made Man: Human Evolution From Eden to Extinction? 1st Edition. New York: Wiley; 1993.

7. Trivers RL. The evolution of reciprocal altruism. Q Rev Biol 1971;46(1):35-57.

8. Pinker S. Rules of language. Science 1991;253(5019);530-5.

9. Jackendoff R, Jackendoff RS. Foundations of language: Brain, meaning, grammar, evolution. Oxford: Oxford University Press; 2002.

10. Di Rienzo A. Population genetics models of common diseases. Curr Opin Genet Dev 2006;16(6):630-6

11. Laland KN, Feldman MW. Niche construction: The neglected process in evolution. Princeton: Princeton University Press; 2003.

12. Kreitman M. Methods to detect selection in populations with applications to the human. Annu Rev Genomics Hum Genet 2000;1:539-59

13. Trivers $R$. The evolution of reciprocal altruism. $Q$ Rev Biol 1971;46:35-57 


\section{Cognitive niche}

\section{Djordje Petronić, Igor Vujović}

University of East Sarajevo, Faculty of Philosophy, Department of Psychology, Pale, The Republic of Srpska, Bosnia and Herzegovina

In a joint publication with Alfred Russell Wallace, Charles Darwin presented the theory which stated that all life forms were developed by natural selection in which the fight for survival had the effect similar to artificial intelligence applied to selective breeding. Despite a coincidence of views concerning the origin of life, these two scientists had their disagreements. Wallace argued that intelligence could have never arisen through the process of natural adaptation, but rather as a consequence of intelligent design. On the other hand, Darwin insisted that human intelligence could only be explained by the theory of evolution. This difference in point of views on the matter is a manifestation of the difference in the efforts to answer the question: "Why are people so intelligent?"

In this context, the main aim of the study is to present a literature review concerning evolutionary psychology and to provide an explanation of the evolution of human intelligence. In other words, the study seeks to explain why people are able to accomplish such intellectual exploits as the ones found in mathematics, science, philosophy, law, etc., bearing in mind that such abilities or talents cannot be found in the original human habitat. The results have showed that evolutionary psychologists consider humans to be so intelligent due to the fact that they have evolved to fill the "cognitive niche". The cognitive niche is a survival mode characterized by managing the environment through mediating cognition and social cooperation.

Keywords: intelligence, cognitive niche, evolution, adaptation 